BMJ Open

Ophthalmology

\section{Disposable versus non-disposable tonometer prisms: a UK national} survey
To cite: Jasani KM, Putri C, Pearl A, et al. Disposable versus non-disposable tonometer prisms: a UK national survey. BMJ Open Ophth 2017;1:e000019. doi:10.1136/bmjophth-2016000019

Received 11 July 2016 Revised 11 February 2017 Accepted 14 February 2017

\section{CrossMark}

\footnotetext{
${ }^{1}$ Manchester Royal Eye Hospital, Manchester, UK ${ }^{2}$ Royal Preston Hospital, Preston, UK

${ }^{3}$ Wills Eye Hospital, Philadelphia, Pennsylvania, USA

${ }^{4}$ Aintree University Hospitals NHS Foundation Trust, Liverpool, UK
}

Correspondence to Dr Kirti M Jasani; kirtijasani@ hotmail.com

\section{ABSTRACT}

Purpose: To determine the prevalence of disposable tonometer versus non-disposable tonometer use in the UK and to determine methods of decontamination and frequency of replacement of prisms.

A total of 137 ophthalmology departments were interviewed by telephone using a structured questionnaire. The main outcome measured were:

- types of tonometer prisms used in clinic (disposable, non-disposable and/or other)

- average disposable prisms used per clinic session

- average lifespan of non-disposable prisms

- prism preference by glaucoma and other teams within department.

A cost and benefit analysis was then performed on the data acquired.

Results: One hundred and fifty-five departments were identified for the survey. Of these, 137 (88.3\%) responded. Eighty-one departments $(59.1 \%)$ used Tonosafe prisms alone, whereas 22 departments (16.1\%) used Goldmann non-disposable prisms exclusively. Thirty-five departments (64\%) on average have a change rate of $26.5 \%$ per year (range: $0-100$, median: 20) attributed to damage, loss or theft. Sixteen departments $(29 \%)$ reported that prisms were used until damaged or lost. Four departments (7\%) were uncertain of their prism usage and could not provide further information.

Conclusions: Majority of eye departments in the UK opt for disposable prisms. This survey shows the perceived cost-effectiveness of disposable prisms is overestimated when the true cost of disinfection and damage is taken into account. Significant cost savings coupled with the low risk of infectivity (if decontaminated properly) should prompt clinicians and ophthalmic departments worldwide to reconsider the use of non-disposable prisms.

\section{PURPOSE}

Applanation tonometry is standard practice in UK eye units for measuring intraocular pressure (IOP), and the Goldmann tonometer has been widely regarded as the gold standard. These tonometers require the placement of a prism and its applanation onto the corneal surface to obtain a reading

\section{Key messages}

There has been a gradual shift and push in using disposable tonometer prism heads throughout eye units in the country, primarily due to concerns of cross infection and contamination.

There is limited clinical evidence supporting transmission of infectious diseases by nondisposable tonometer prisms if appropriate precautions are used in addition to the significant cost savings it offers to departments using them.

We believe that the perceived cost-effectiveness and safety of disposable prism is probably overestimated and that switching to nondisposable ones will result in significant cost savings to the National Health Service without compromising patient safety.

for IOP. Up to recently, non-disposable prisms were the preferred choice in the majority of eye departments in the UK. ${ }^{1} 2$

However, there have been reports of outbreaks of epidemic viral ocular infections in ophthalmic clinics worldwide. ${ }^{3-5}$ Epidemiological and clinical studies of epidemic keratoconjunctivitis in eye clinics have identified possible contamination with tonometer tips, eye drop bottles and contact with infected healthcare workers as vehicles of transmission (particularly of adenoviral serotypes). 67

Insufficient disinfection of Goldmann tonometer prism heads has been postulated as a possible significant cause of transmission. In addition, improper sterilisation techniques can also increase the risk sustaining a corneal injury due to residual cleaning agent on re-usable prism heads.

A recent publication by Haag-Streit (a manufacturer of Goldmann tonometers) found that the mean age of non-disposable prisms in the UK was 9.8 years, with $56 \%$ of 
these being damaged or scratched. ${ }^{8}$ These factors, along with the recommendations by the Medical Device Agency advice that 'components of ophthalmic devices that touch the surface of the eye should be restricted to single patient use where practicable and where this does not compromise clinical outcome', led to the introduction of disposable (single-use) prism heads, which were felt to be safer, as effective and equally reliable to the re-usable Goldman prisms. ${ }^{4}$ Interestingly, Haag-Streit is also the manufacturer of Tonosafe disposable prisms, one of the most popular disposable prism brands in the UK.

The notion of 'perceived safety' and evidence showing comparable accuracy and cost between both prism heads have led to a gradual but definite shift to the use of disposable prisms worldwide. ${ }^{3} 489$ The primary aim of this survey was to compare the use of disposable versus non-disposable prisms and to determine the cost-benefits of each in current UK practice.

\section{METHODS}

A list of all ophthalmology units with training recognition in England, Northern Ireland, Scotland and Wales was obtained from the Royal College of Ophthalmologists (RCOphth) Directory of Training Posts in Ophthalmology 2015. A prospective survey was designed and the units were contacted via telephone to answer questions from the survey. At each institution, a senior nurse or sister who was familiar with the daily functioning of the outpatient ophthalmology clinic responded to this structured telephone questionnaire (table 1). If the staff member was unable to provide an answer on the first telephone call, or if there was no answer, a second call was made at a more convenient time. If a telephone call was not possible, some were able to send a reply by email. In institutions and hospitals where there was no response after the second call, no further attempts were made. A cost analysis was performed on the data collected to determine the most effective alternative.

Table 1 Proforma used for recording data from ophthalmology units nationwide

\section{Proforma for Goldmann tonometer survey}

\begin{tabular}{lll}
\hline Department & & \\
Prism & Disposable & Prisms used/clinic \\
& Non-disposable & Average lifespan/prism \\
& Other & \\
Preference & Glaucoma team \\
& Others \\
\hline
\end{tabular}

RESULTS

A total of 155 eye units were identified and contacted. The responses were obtained from 137 departments, with a response rate of $88.3 \%$.

Eighty-one departments $(59.1 \%)$ reported exclusive use of the disposable Tonosafe prisms, whereas 22 departments $(16.1 \%)$ used Goldmann non-disposable prisms exclusively. Thirty-three departments (24.1\%) used a combination of both and one department $(0.7 \%)$ used mainly Tonojet prisms.

Out of 33 units that used a combination of prisms, 28 used a combination of Goldmann and Tonosafe, four used Goldmann and Tonojet, and one used Goldmann and Tono-Pen. In 18 of these units the glaucoma teams specifically preferred the use of Goldmann prisms and in one unit they preferred Tonosafe disposable prisms. The remaining 15 units were unable to quote a preference during the survey.

In total, 55 departments used the Goldmann tonometer primarily or in combination with another prisms to measure IOP. Thirty-five departments $(64 \%)$ on average have a change rate of $26.5 \%$ per year (range: 0-100, median: 20), and this was mainly due to damage, loss or theft. Sixteen departments (29\%) were unable to quote a prism change rate/year but said prisms were used until they were damaged or lost. Four departments $(7 \%)$ were uncertain of their prism usage and could not provide any further information.

On the basis of the results we know that the average replacement rate of non-disposable tonoprisms is 26.5\% per year. The most recent data from Hospital Episode Statistics, as published on the Health and Social Care Information Centre website, reveal that there were just over sixmillion patient visits to ophthalmic outpatients in the UK in 2015 (Hospital Episode Statistics for England). ${ }^{10}$

Assuming that applanation tonometry was only performed on half of these visits, an estimation of the overall costs to compare non-disposable with disposable prisms can be made. The list price for a box of 100 Tonosafe prisms is $£ 72.50$. The cost of three million Tonosafe prisms works out at £2 175000.00 , which would amount to the annual cost for the whole of the UK if Tonosafe prisms were used exclusively for $50 \%$ of patient visits.

For the use of non-disposable prisms, if we assume that (1) applanation tonometry was performed at three million visits in 2015, with each examination room possessing two non-disposable prisms, and (2) each room is used daily and has traffic of about 24 patient visits per day, the total yearly patient visits would be 6240 per room (per two non-disposable prisms). So for three million episodes, 480 examination rooms are required using a total of 960 prisms UK-wide. Based on these assumptions and a list price of $£ 128.50$ for a non-disposable Goldman prism, the initial outlay nationwide in the first year would be £123 360.00. Supposing that visit numbers remain the same the 
following year and that the replacement rate of nondisposable prisms is $26.5 \%$, the cost for subsequent years would be $£ 32767.50$ (255 prisms). These assumptions do not include any costs associated with cleaning of prisms and regular inspection as we regard these to be inconsequential for most departments as these solutions would already be prepared in readiness for the disinfection of ophthalmic contact lenses.

As an example, we performed a cost comparison at a local district general hospital (DGH). At this DGH, disposable tonometer prisms and the Tono-Pen were used to assess IOP. A total of 46500 patients were seen in the outpatient department in 2013. Assuming that only half of these patients had tonometry, the cost would be $£ 16856.25$ for disposable prisms per year. If we assume that tonometry was performed in all cases, the cost would be $£ 33712.50$ per year.

In comparison, if non-disposable prisms were used exclusively, the initial outlay of 30 prisms to stock 15 examination rooms would amount to an initial cost of $£ 3855$, followed by a yearly cost of only $£ 1028$ (assuming an annual replacement rate of $26.5 \%$, ie, eight prisms). Therefore, even if $50 \%$ of patient visits required tonometry, this switch to non-disposable prisms would make a cost saving of at least $£ 15000$ per year.

\section{DISCUSSION}

Based on the findings of this paper, potentially $£ 2$ million could be saved nationwide if non-disposable prisms are used alone. Still, if the estimated costs per year for non-disposable prisms are doubled, a similar saving of $£ 2$ million can still be achieved. There is a clear cost-benefit to using non-disposable prisms.

Best current evidence shows that the clinical incidence of infections transmitted by non-disposable tonometers is low and limited to less invasive microorganisms. Laboratory studies have shown that viruses such as Herpes simplex virus (HIV), Hepatitis B and Hepatitis C can be isolated from the tonometer tip and grown in laboratory settings. However, there is no definitive clinical evidence that supports the transmission of these pathogens via contaminated ophthalmic equipment. Furthermore, these laboratory-based tests are highly sensitive and may overestimate the clinical morbidity experienced by patients. ${ }^{11}$

There is currently a lack of evidence supporting transmission of infectious diseases by tonometers if appropriate precautions are used. The RCOphth has produced specific guidance on ophthalmic instrument decontamination in clinics, including that of tonometry prisms. ${ }^{12}$ This suggests that it is unnecessary to use disposable prisms for all routine cases but suggests their use in 'potential risk' patients such as those known to have or under suspicion of having Creutzfeldt-Jakob disease (CJD). The guidance deems it acceptable to use re-usable tonometer prisms provided that they are decontaminated correctly between patients.

However, infection control and contamination teams in many hospitals undertake risk assessments for infection, and it is these teams that dictate the use of disposable equipment including tonometers. With hospitals being measured so stringently on infection rates, these teams, which usually comprise the nonophthalmic staff, have the authority to impose practice in many areas of care. When taking this into account, the relative cost-benefits may still be outweighed by litigation over injury or infection sustained with the use of non-disposable prism heads. However, no National Health Service (NHS) litigation report involving crossinfections caused by tonometer heads have been reported in the last 10 years. ${ }^{13}$

Furthermore, a local survey in the UK showed that disposable prisms do not completely prevent the spread of bacterial or viral infections, as almost $50 \%$ of staff admit to touching the applanating face of the disposable prisms during use. ${ }^{14}$

A US study has shown that both prisms have similar efficacy and accuracy in measuring IOP even though the glaucoma teams in our survey favoured the use of re-usable prisms if these were available. In the same study the increased cost of non-disposable prisms was derived from the added cost of cleaning solution and labour involved for disinfection. ${ }^{8}$ However, in most UK departments, the cleaning solution is routinely provided for disinfecting contact lenses and as such does not represent any additional cost.

The evidence on the use of disinfectants when cleaning the tonometer tip shows no statistically significant difference in bacterial elimination when compared with wiping with sterile gauze or a clean tissue. ${ }^{15} 16$ There are also concerns regarding the safety of disinfectants used to clean the tonometer heads on ocular surfaces, with reports of corneal toxicity and epithelial changes following the use of chlorine-based disinfectants, adding to the growing scepticism and concerns on their long-term effects. Re-usable tonometer prisms can also become damaged with time and regular inspection at the slit-lamp is recommended, with replacement of any prism with significant damage. ${ }^{17}$

The evidence so far appears to indicate that the use of non-disposable prisms (with adequate disinfection) is safe and reliable. Providing that high-risk patients are identified and disinfection protocols are adhered to, this option may also be more cost-effective.

As with most telephone surveys, a potential source of error with this prospective survey is the reliance on the information provided verbally by the nursing staff over the telephone. We attempted to overcome this by verifying that each nurse completing the questionnaire was familiar with the daily running of the clinic and felt capable of providing accurate information based on the questions asked. 
There is a significant convenience factor associated with the use of disposable tonometers that cannot be ignored. The use of disposable prisms offers a degree of independence to doctors, as there is less reliance on the availability of sterilising solutions in addition to the savings on time taken for sterilisation. There is also reduced dependency on nursing staffs who are generally thin on the ground, particularly in the outpatient department.

In addition, a confounding factor not taken into account in our calculations is patients who have their IOPs measured several times in one visit, for example patients with acute angle-closure glaucoma. These patients may need a new disposable prism at each measurement, resulting in further cost to the department.

\section{CONCLUSION}

This survey shows the varying use of tonometer prisms within the UK and demonstrates that the perceived cost-effectiveness of disposable prisms is probably overestimated when one calculates the true costs of disinfection and damage.

We also found that there is no uniformity in the use of non-disposable and disposable prisms in the UK, with some departments using both. The RCOphth has recently advised that the use of non-disposable prisms is acceptable when decontaminated properly. Given this advice and the significant cost-benefit of using non-disposable prisms in comparison with disposable prisms, we feel that continuing to use or switching to non-disposable prisms will result in significant cost savings in these difficult financial times for the NHS.

Despite the fact that the clinical incidence of transmitting virulent infections from use of contaminated tonometer tips has remained very low, we would still recommend that high-risk cases be identified (those patients known to have or suspected to have CJD) and it would be prudent to use disposable prisms for these cases.

Acknowledgements The authors would like to acknowledge the valuable time provided by the nursing staff in various ophthalmic hospitals in the UK in providing the data when surveyed.

Contributor $A B$ and $K J$ contributed to the concept and design of the survey. $\mathrm{KJ}, \mathrm{CP}, \mathrm{AP}$ and NS contributed to the acquisition of data. Data analysis was performed by $\mathrm{KM}$ and $\mathrm{KJ}$, who also wrote the initial draft of the paper. $\mathrm{KJ}, \mathrm{CP}$, GS and $A B$ critically revised the paper. All authors approved the final version of the paper.

Competing interests None declared.
Provenance and peer review Not commissioned; externally peer reviewed.

Open Access This is an Open Access article distributed in accordance with the Creative Commons Attribution Non Commercial (CC BY-NC 4.0) license, which permits others to distribute, remix, adapt, build upon this work noncommercially, and license their derivative works on different terms, provided the original work is properly cited and the use is non-commercial. See: http:// creativecommons.org/licenses/by-nc/4.0/

(C) Article author(s) (or their employer(s) unless otherwise stated in the text of the article) 2017. All rights reserved. No commercial use is permitted unless otherwise expressly granted.

\section{REFERENCES}

1. Hillier RJ, Kumar N. Tonometer disinfection practice in the United Kingdom: a national survey. Eye 2008;22:1029-33.

2. Ng J, Kashani S, Qureshi K, et al. Intraocular pressure measurement and Goldmann calibration. an eye opening review of practice in United Kingdom. Eye 2007;21:851-3.

3. Thomas V, Daly MK, Cakiner-Egilmez T, et al. Reliability of tonosafe disposable tonometer prisms: clinical implications from the veterans affairs Boston healthcare system quality assurance study. Eye 2011;25:651-6.

4. Goel S, Chua C, Dong B, et al. Comparison between standard Goldmann applanation prism and disposable applanation prism in tonometry. Eye 2004;18:175-8.

5. Warren D, Nelson KE, Farrar JA, et al. A large outbreak of epidemic keratoconjunctivitis: problems in controlling nosocomial spread. J Infect Dis 1989;160:938-43.

6. Centers for Disease Control (CDC). Epidemic keratoconjunctivitis in an ophthalmology clinic-California. MMWR Morb Mortal Wkly Rep 1990;39:598-601.

7. Viney KA, Kehoe PJ, Doyle B, et al. An outbreak of epidemic keratoconjunctivitis in a regional ophthalmology clinic in New South Wales. Epidemiol Infect 2008;136:1197-206.

8. Dean J. Average age and condition of prisms white paper. Haag Streit United Kingdom (HSUK). 2012. http://info@haag-streit-uk.com

9. Kim P, Lertsumitkul S, Clark M, et al. Accuracy of the tonosafe disposable tonometer head compared to the Goldmann tonometer alone. Clin Exp Ophthalmol 2004;32:364-7.

10. Health and Social Care Information Centre. Hospital Episode Statistics for England 2014-15. http://www.hscic.gov.uk/ article/2021/Website-Search?productid=19879\&q=outpatients\&sort= Relevance\&size=10\&page=1\&area=both\#top (accessed 8 Mar 2016).

11. Arora S, Roelofs K, Damji KF. Tonometer tip disinfection: principles, evidence, and importance of end-user engagement in policy formulation. Can J Ophthalmol 2013;48:136-9.

12. Hingorani M. Royal College of Ophthalmologists (RCOphth) Ophthalmic services guidance. Ophthalmic instrument decontamination. 2016 https://www.rcophth.ac.uk/wp-content/ uploads/2014/12/Ophthalmic-Instrument-Decontamination.pdf (accessed 30 Oct 2016).

13. NHS Litigation Authority. NHSLA result of data interrogation FOI_2105. 2014 http://www.nhsla.com/aboutus/Documents/NHS\% 20LA\%20Annual\%20Report\%20and\%20Accounts\%202013-14.pdf (accessed 21 Mar 2016).

14. Rajak SN, Paul J, Sharma V, et al. Contamination of disposable tonometer prisms during tonometry. Eye 2006;20:358-61.

15. Corboy JM, Borchardt KA. Mechanical sterilization of the applanation tonometer. 1. bacterial study. Am J Ophthalmol 1971;71:889-91.

16. Cheng LY, Portocarrero CM, Lopez CMG, et al. Efficacy of isopropyl alcohol $70 \%$ versus sodium hypochlorite for Goldmann tonometer disinfection in a clinical setting. V Pan America 2007;6:14-16.

17. Kniestedt C, Stürmer J, Stamper RL. Clinical alert: damage to Goldmann applanation tonometer tips. Acta Ophthalmol Scand 2005;83:129-30. 